\title{
Rapid-acting antidepressants and the circadian clock
}

\author{
Shogo Sato ${ }^{1,2}$, Blynn Bunney ${ }^{3}$, Lucia Mendoza-Viveros ${ }^{4,5}$, William Bunney ${ }^{3}$, Emiliana Borrelli (D) ${ }^{6}$, Paolo Sassone-Corsi ${ }^{2,7}$ and \\ Ricardo Orozco-Solis (iD ${ }^{5^{凶}}$
}

(c) The Author(s), under exclusive licence to American College of Neuropsychopharmacology 2021

A growing number of epidemiological and experimental studies has established that circadian disruption is strongly associated with psychiatric disorders, including major depressive disorder (MDD). This association is becoming increasingly relevant considering that modern lifestyles, social zeitgebers (time cues) and genetic variants contribute to disrupting circadian rhythms that may lead to psychiatric disorders. Circadian abnormalities associated with MDD include dysregulated rhythms of sleep, temperature, hormonal secretions, and mood which are modulated by the molecular clock. Rapid-acting antidepressants such as subanesthetic ketamine and sleep deprivation therapy can improve symptoms within $24 \mathrm{~h}$ in a subset of depressed patients, in striking contrast to conventional treatments, which generally require weeks for a full clinical response. Importantly, animal data show that sleep deprivation and ketamine have overlapping effects on clock gene expression. Furthermore, emerging data implicate the circadian system as a critical component involved in rapid antidepressant responses via several intracellular signaling pathways such as GSK3 $\beta$, mTOR, MAPK, and NOTCH to initiate synaptic plasticity. Future research on the relationship between depression and the circadian clock may contribute to the development of novel therapeutic strategies for depression-like symptoms. In this review we summarize recent evidence describing: (1) how the circadian clock is implicated in depression, (2) how clock genes may contribute to fast-acting antidepressants, and (3) the mechanistic links between the clock genes driving circadian rhythms and neuroplasticity.

Neuropsychopharmacology (2022) 47:805-816; https://doi.org/10.1038/s41386-021-01241-w

\section{INTRODUCTION}

Major depressive disorder (MDD) is one of the most serious psychiatric disorders. Worldwide, depression affects over 300 million people of all ages and is the leading cause of lifetime disability out of all medical disorders according to the World Health Organization (WHO) [1, 2]. Approximately 800,000 individuals die from suicide each year, many of which are associated with MDD $[2,3]$. In the United States, the burden of MDD increased substantially over the past decade in terms of prevalence, the stress associated with COVID-19, rising economic costs and importantly, the limited efficacy of standard antidepressants [4]. Fast-acting interventions such as subanesthetic ketamine or sleep deprivation therapy (SDT) (e.g., $36 \mathrm{~h}$ of continuous wakefulness [5]) can effectively decrease suicidality within hours [6], thereby potentially saving many lives. The therapeutic limitation of classic antidepressants including limited efficacy ( 50\%), low remission rates ( 30-40\%) in addition to the prolonged response delay of several weeks [7] suggests that additional mechanistic factors may contribute to the pathophysiology of MDD.

Emerging evidence supports a circadian hypothesis of depression based, in part, on data showing that a subgroup of depressed patients (20-30\%) has dysregulated $24 \mathrm{~h}$ rhythms including sleep, core body temperature, hormonal secretions (i.e., cortisol, melatonin) and mood. Moreover, rhythms may normalize as symptoms remit [8-14]. Diurnal fluctuations in mood in a subgroup of depressed patients include a pattern of depressive symptoms that are significantly worse in the morning and dramatically improve by evening [6]. Perhaps the strongest and most direct evidence for a circadian defect in depression comes from a study of postmortem $24 \mathrm{~h}$ sinusoidal gene expression rhythms across six regions of human brain showing a dramatic dysregulation of circadian genes in MDD compared to controls [15]. The analysis supports the hypothesis that the disruption of the circadian expression of the essential genes running the circadian clock (i.e., core-clock genes) and the genes that they control (clock-controlled genes- CCGs) have an impact on the functional regulation of numerous neuronal processes and behaviors including mood [15].

The circadian clock, in addition to its canonical role in the regulation of circadian rhythms, participates in the control of diverse brain functions, including memory formation, astrocytemediated circadian behavior, sleep homeostasis, and energy balance [16-20]. More than $90 \%$ of depressed patients report disruptions in sleep including insomnia and early morning awakening. These patients tends to have more severe forms of

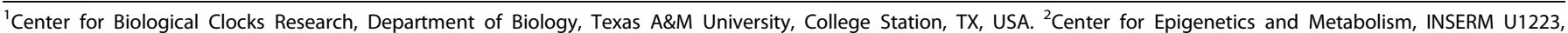

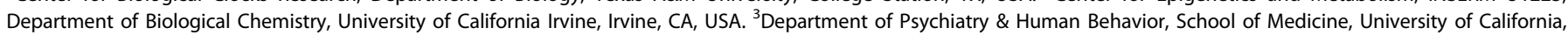

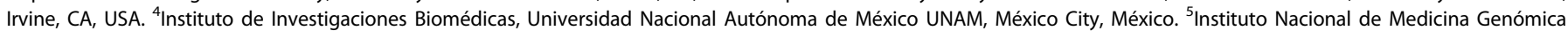

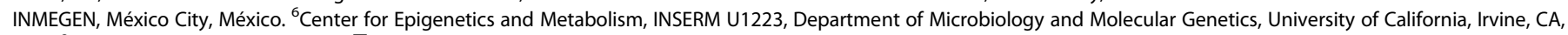
USA. ${ }^{8}$ Deceased: Paolo Sassone-Corsi. ${ }^{\bowtie}$ email: drorozcos@inmegen.gob.mx
} 


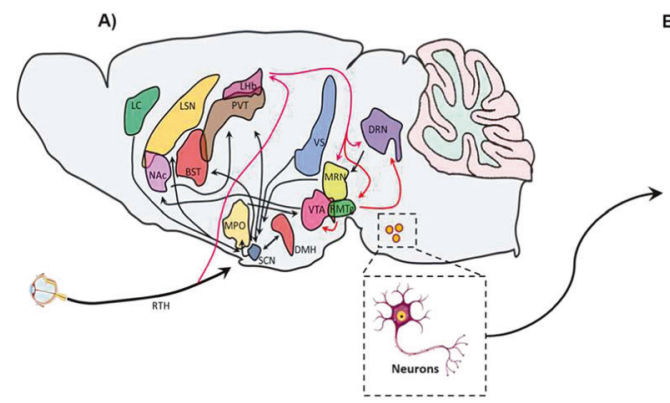

B)

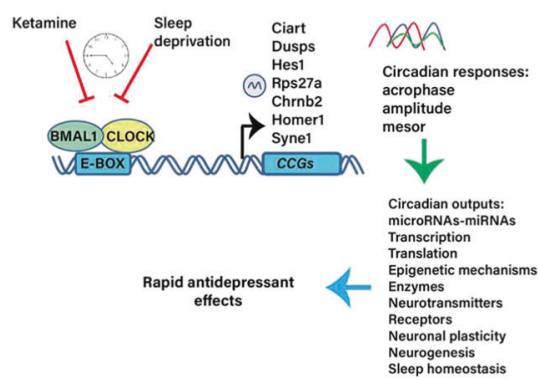

Fig. 1 Organization of the circadian clock. A Representative schema depicting efferent and afferent signaling to the suprachiasmatic nucleus (SCN) (black arrows). These include limbic structures including the infralimbic cortex (LC), lateral septal nucleus (LSN), basal forebrain of the stria terminalis (BST), ventral subiculum (VS), paraventricular thalamic nuclei (PVT), nucleus accumbens (NAc), ventral tegmental area (VTA), medial preoptic nucleus (MPO), dorsal raphe nucleus (DRN), median raphe nucleus (MRN) and hypothalamic nuclei [i.e., dorsomedial hypothalamus $(\mathrm{DMH})$, and the retino-hypothalamic tract $(\mathrm{RHT})][28,30]$. The lateral habenula $(\mathrm{LHb})$ efferent and afferent connections are shown (red arrows), ventral lateral geniculate (Vlgn), intergeniculate leaflet (IGL), rostromedial tegmental nucleus (RMTg) [25, 28, 34, 116, 220]. B A predictive model in which ketamine and sleep deprivation elicit common transcriptional responses by blocking BMAL1/CLOCK function at specific times of the day (Zeitgebers-ZTs) associated with neuronal and behavioral responses [94, 95, 219]. Changes in the acrophase and/or amplitude of the CCGs participating at different regulatory levels could affect mood. The 7 clock-controlled genes represent potential components of rapid antidepressant actions of ketamine and sleep deprivation.

MDD, are less likely to have full clinical responses to standardized treatments and may be at an increased risk for suicidal ideation and suicidal behaviors (for review, [21]).

Genetic and transcriptomic data provide convincing evidence linking circadian gene polymorphisms with an increased risk for depression [15, 22, 23]. Studies in rodent models of depressive-like behaviors highlight the complex interactions of the circadian system in mediating rapid antidepressant responses [24-26]. In this review, we summarize the rapid-acting mechanisms of action of subanesthetic ketamine and sleep deprivation and their effects on clock function, neuronal plasticity, sleep homeostasis, and neurogenesis.

\section{THE CIRCADIAN CLOCK}

Circadian rhythms control virtually all physiological, behavioral, and metabolic processes. In mammals, the suprachiasmatic nucleus (SCN) located in the hypothalamus serves as the central pacemaker, which is synchronized daily by light cycles via input from the retino-hypothalamic tract. The SCN in turn synchronizes peripheral clocks in other brain areas and peripheral organs to orchestrate circadian rhythms, through synaptic connections, autonomic innervations, and endocrine signaling [27]. The SCN can also be influenced by non-photic inputs including behavior, nutritional intake, exercise and social contact [27]. Moreover, on an anatomical level, the SCN is capable of receiving, integrating and sending information to an estimated 85 brain areas, resulting in the regulation of higher brain function [28] (Fig. 1A). Viral transneuronal labeling techniques in rats identified six afferent projections to the SCN including the retina, limbic system, hypothalamus, raphe nuclei, paraventricular thalamus, and extra retinal visual system [29]. Importantly, interactions between the SCN and limbic structures including the infralimbic cortex, lateral septal nucleus, bed nucleus of the stria terminalis, ventral subiculum, paraventricular thalamic nucleus, dorsal raphe nucleus (DRN) median raphe nucleus and lateral habenula (LHb), comprise critical circuitries that impact higher brain function [30]. Additionally, the peri-habenular nucleus, a recently identified region, serves as a link between intrinsically photosensitive retinal ganglion cells (ipRGCs) (expressing the photopigment melanopsin) and an SCN-independent pathway, to regulate affective behavior [31]. LHb neurons show daily firing-activity patterns, suggesting that the LHb likely relays circadian outputs through efferent projections to forebrain and midbrain aminergic nuclei [32-34]. The LHb is not considered an autonomous pacemaker since it depends on SCN innervation and light information to maintain synchrony [35]. Light/dark environmental signals can trigger changes in circadian rhythmicity related to antidepressant efficacy of light therapy as demonstrated by light-mediated induction of Per1 in the LHb. In contrast, long-term exposure to dark can transiently desynchronize SCN and habenular rhythms (dark-associated depressive-like symptoms are reversible by antidepressants) [36].

At the molecular level, the circadian clock consists of a network of interlocked transcriptional-translational feedback loops (TTFL). The core proteins within the TTFL are the transcription factors, Circadian Locomotor Output Cycles Kaput (CLOCK), and BMAL1. These transcription activators heterodimerize and rhythmically bind to E-box promoter elements and activate the clockcontrolled genes (CCGs) (Fig. 1B). Among the CCGs, PERIOD 1-3 (PER 1-3), and CRYPTOCHROME 1 and 2 (CRY1 and 2) repress the transcriptional activity driven by CLOCK/BMAL1, and inhibit their own expression through a negative autoregulatory feedback loop that cycles in $\sim 24 \mathrm{~h}[27,37]$. The CCGs encode transcriptional regulators, including the D-box binding protein (DBP), thyrotroph embryonic factor (TEF), retinoic acid-related orphan receptor $\mathrm{a} / \mathrm{b} / \mathrm{c}$ $(R O R a / \beta / \gamma)$ and REV-ERBa/ $\beta$ (reverse erythroblastosis virus $\alpha / \beta$ ). DBP and TEF bind to D-boxes, while RORa $/ \beta / \gamma$ and REV-ERBa/ $\beta$ bind to REV-ERB/ROR promoter elements, in turn, inducing additional circadian waves in the expression of downstream genes. It is estimated that the circadian machinery controls the cyclic expression of about $10-30 \%$ of genes in any given cell $[27,37]$, although recent estimates indicate that many more genes may exhibit robust oscillations in response to nutritional and metabolic inputs to modulate the organization of circadian physiology $[27,38]$.

Moreover, neurotransmitters, hormones, metabolites, nutrients, humoral and environmental inputs interconnect cellular signals with the molecular clock [39-41]. For example, synchronous astrocytes have the capability of entraining rhythmicity in neurons via GABA signaling [42]. When rhythms are disrupted, (e.g., varied light/dark cycles, jet lag) interference with central and peripheral clock function can lead to abnormal clock gene rhythms [43] and increase the risk for physical and psychiatric disorders including depression $[6,13,15,44,45]$.

Sleep deprivation therapy (SDT) and subanesthetic ketamine: clinical data and circadian mechanisms

Sleep deprivation therapy (SDT). SDT has been recognized as an effective treatment for depression $[46,47]$. Its rate of efficacy, estimated to be at $40-60 \%$ efficacy is comparable to that of monoaminergic drugs but with a much faster onset (within $24 \mathrm{~h}$ ). 
In Europe SDT is often used as a first line treatment but less frequently in the United States [48]. Although high relapse rates (return of depressive symptoms following a night of recovery sleep) are a major limitation, improvement can be sustained for several weeks with the administration of non-pharmacological circadian interventions of bright light therapy, and sleep phase advance $[49,50]$. While the mechanism of SDT remains largely unknown, the sleep homeostasis hypothesis proposes that sleep is associated with synaptic downscaling, a weakening of synaptic strength thought to involve metabotropic glutamate receptors, while wakefulness facilitates synaptic potentiation [51, 52]. Moreover, in vivo two-photon imaging show that dendritic spine morphology is constantly changing during both wakefulness and sleep as demonstrated in rat pyramidal cells of the sensorimotor cortex [53]. Therefore, it is conceivable that extended wakefulness contributes to the antidepressant effects of SDT by promoting synaptogenesis.

Sleep is regulated by circadian (diurnal timing of sleep) and homeostasis (sleep pressure) processes. Circadian regulation of sleep is reported to be independent of prior wakefulness, differentiating it from homeostasis, although data in humans and rodents suggest an interaction. Insomnia affecting about $90 \%$ of depressed patients, is characterized by difficulty in falling asleep, staying asleep, early morning awakening and/or shortened rapid eye movement (REM) latency-symptoms compatible with a shift in circadian phase. Chronic insomnia is associated with an increased risk for recurrent depressive episodes as well as suicidality while normalization of sleep patterns may be an early predictor of antidepressant response [6, 21].

Clinical research has implicated the response to sleep deprivation associated with variants in serotonin-related pathways, (5HT2A, rs6313, 5HTTLPR) [54, 55], the serine-threonine kinase GSK3 $\beta$ [56] and the core-clock gene Per3 [57]. A genome-wide study of SDT in MDD and BP patients [58] showed post-SDT alterations in circadian genes (Bmal1, Per2, Per3, and Nr1d1) [58]. Of potential relevance is that we found that this subset of genes were abnormally expressed in MDDs across six brain areas compared to controls [15].

Studies in rodents suggest that astrocytes a subtype of glial cell are an important contributor to antidepressant actions of sleep deprivation specifically involving the adenosine receptor, A1 (A1R) $[59,60]$. Importantly, astrocytes are key contributors to sleep homeostasis. When sleep need is high, astrocytes release chemical transmitters such as adenosine, that presynaptically inhibit excitatory transmission and induce slow-wave activity in rodent brain [61-63]. Furthermore, in the SCN, astrocytes contribute to pacemaker properties by relaying glutamatergic and ATP signals to neurons at night [64]. For example, astrocytic expression of clock genes modulate broad network fluctuations in glutamate in the sleep/wake network [65].

Ketamine. Subanesthetic ketamine administered intravenously dramatically decreases symptoms within 2-4 h with an efficacy of 70-80\% [66-69]. Maintaining improvement longer than 1 week post-infusion has motivated strategies for sustaining responses including administering repeated doses [70] and adding adjunctive treatments [71]. Subanesthetic ketamine is also shown to decrease suicidal ideation as reported in double-blind studies in depressed patients $[72,73]$. The moderate hour-long psychotomimetic side effects of ketamine are transient and may include hallucinations, dreamlike states, confusion, gaps in memory and out of body experiences. Ketamine has two enantiomers, (S) and (R); intranasal esketamine (S-ketamine) has been recently approved by the FDA [74].

Ketamine is a noncompetitive high-affinity N-methyl-Daspartate receptor (NMDAR) antagonist, selectively blocks GluN2B-containing NMDAR on inhibitory GABAergic interneurons. This allows the disinhibition of glutamatergic transmission, which in turn activates postsynaptic AMPA receptors and intracellular signaling pathways inducing plasticity [68, 75-79]. When the AMPA antagonist NBQX (2,3-dioxo-6-nitro-7-sulfamoyl-benzo[f] quinoxaline) is administered prior to ketamine injection (i.p.), the ability of ketamine to decrease depressive-like behavior in rodents is blocked $[68,80]$. It is also postulated that ketamine could block the GluN2B component of the NMDA, thereby reducing the activation of the elongation factor-2 kinase (eEF2K) to prevent the phosphorylation of eEF2, thus inducing the translation of BDNF [76]. The BDNF-TRKB pathway activates the mammalian target of rapamycin complex 1 (mTOR1) [81-83]. mTOR, a signal integrator and neuronal response regulator, modulates the production of proteins required for the formation of spines and synapses [81]. This process underscores another intriguing interplay: mTOR signaling is controlled by the circadian clock, leading to the cyclic regulation of protein synthesis $[84,85]$. In the SCN, mTOR participates in the light-induced translation of the core-clock and CCGs including PER1-2 and VIP (vasoactive intestinal peptide). This is achieved by phosphorylating and inhibiting the translation repressor elF4E binding protein (4E-BP), releasing the translation initiation factor $4 \mathrm{E}$ (elF4E), and by activating translational effectors such as ribosomal proteins including $\mathrm{S} 6$ kinases [86]. Strikingly, the core-clock protein BMAL1 acts as a translation factor by interacting with the translational machinery and promoting protein synthesis, and this mechanism is modulated by mTOR via phosphorylation of BMAL1 at Ser42 [87].

The BDNF-TRKB pathway is induced by both classic monoaminergic antidepressants and fast-acting ketamine, by directly binding to TrkB [88], implying that classic, and glutamatergic antidepressants may share some common mechanisms. For instance, the TrkB gene is expressed in a circadian manner, which could be controlled directly by BMAL1/CLOCK, as suggested by the presence of E-box sites within its promoter [89]. Moreover, the melatonin precursor $\mathrm{N}$-acetylserotonin (NAS) activates the TrkB pathway resulting in antidepressant-like effects in rodents [90]. Furthermore, daily TrkB activity follows a circadian pattern [90], suggesting that the circadian clock further modulates the TrkB pathway via neuronal plasticity.

Chronotherapeutics have gained traction as a strategy to increase antidepressant efficacy when treatment is administered in synchronicity with specific phases of the circadian clock. It is hypothesized that a novel mechanism of action of ketamine is to restore depression-related glial defects by modulating the density and distribution of cholesterol in the plasmalemma of astrocytes via interactions with cholesterol, BDNF and TrkB [88, 91, 92]. BDNF increases cholesterol signaling in neurons while cholesterol regulates TrkB signaling. Although biomarkers of cholesterol (i.e., lathosterol, mevalonate, squalene) have nocturnal peaks in expression, the absorption rates of cholesterol do not vary [93]. Nevertheless, further research can help determine whether the timing of ketamine administration as a function of peak cholesterol levels could increase antidepressant efficacy.

We demonstrated that ketamine represses circadian expression of clock genes Bmal1, Per2, Cry1, and Dbp in mouse fibroblast cell culture by decreasing binding of CLOCK/BMAL1 to its target promoters. The binding capacity of CLOCK/BMAL1 to its target promoter DBP was inhibited at circadian time 24 (CT24) $1 \mathrm{~h}$ posttreatment, paralleling its transcriptional inhibition. We estimated that the inhibitory effect lasted only a few hours as no effects were observed at other CTs [94].

Rodent and human data appear to be comparable in terms of timing of ketamine antidepressant actions. In rodents, ketamine was shown to reduce depressive-like behavior starting $30 \mathrm{~min}$ postinjection (paralleling changes in BDNF and mTOR levels in the hippocampus) with antidepressant effects lasting for several days [81, 83]. For MDD patients, the onset of improvement ranged between 40 and $120 \mathrm{~min}$ and was sustained from $2 \mathrm{~h}$ to 7 days [69]. 


\section{Overlapping effects of ketamine and sleep deprivation}

We hypothesized that SD and KT may share common mechanisms of action that converge on circadian-related processes to accelerate antidepressant responses. We analyzed the anterior cingulate (ACC) in mice treated with either $12 \mathrm{~h}$ sleep-deprived or $8 \mathrm{~h}$ post ketamine injection at a single time point (ZT13) and compared the results to a control group to determine which genes, if any, were shared between the two treatments in the ACC [95]. In support of a circadian role, we identified an overlapping downregulation of circadian genes including Ciart, Per2, Npas4, Dbp, and Rorb in both ketamine and sleep deprivation-treated mice [95]. Though the underlying mechanisms involved in the effects of ketamine and SDT as zeitgebers are unknown, data implicates the BDNF-TrkB pathway since both treatments act on this pathway across several brain areas [76, 88, 96-98]. Moreover, infusion of BDNF in the SCN induces phase advances in the circadian activity of rodents [99]. The BDNF-TrkB pathway also relays light inputs to the central clock [100]; specifically, the transcriptional repressor methyl-CPG binding protein 2 (MECP2 a BDNF regulator) is phosphorylated in response to light within the $\mathrm{SCN}$ via a CaMKII-dependent mechanism, allowing the expression of BDNF [101]. Lei et al. reported that the GluN2B antagonist MK0657 (a component of the NMDA receptor), induces antidepressant effect by reducing BDNF expression and neuronal activity in the LHb [102]. Although not yet well understood, it is postulated that the actions of BDNF on mood or clock regulation is dependent on brain area and/or neuronal subtype [102].

Rapid antidepressant responses in treatment-resistant depressed patients suggest a mechanism that is linked to fast changes in synaptic function and plasticity as demonstrated with the restoration of spine density within hours of treatment with SDT or ketamine $[79,81,103-105]$ It is hypothesized that the induction of synaptogenesis reverses the loss of depressionassociated synaptic connectivity and restores cognitive and emotional function. In contrast to ketamine and SDT, sloweracting antidepressants first target monoamines to promote synaptogenesis [79]. Ketamine has unique properties in its rapid acceleration of synaptic plasticity but may also have actions that overlap with molecular mechanisms that regulate homosynaptic scaling [106] while acute sleep deprivation induces rapid formation of hippocampal dendritic spines [104, 105].

Not surprisingly, ketamine also enhances the monoamine system, including serotoninergic and dopaminergic neurotransmission [88, 107] while sleep deprivation primarily induces dopamine neurotransmission [108, 109]. Thus, both treatments alter the expression of genes related to the dopaminergic synapse, including the G-Protein Subunit Gamma 10 (Gng10, which is part of the heterotrimeric $G$ proteins, involved in intracellular signaling) and the dopamine receptor 5 (D5R), among others [95]. Metabotropic glutamate $(\mathrm{mGlu})$ are receptors coupled to $\mathrm{G}$ proteins and are important for glutamate binding, acting as glutamatergic agonizts. Among the eight $\mathrm{mGlu}$ receptor subtypes, data supports the $\mathrm{mGlu2} / 3$ receptor as a potential therapeutic target for depression [110] although mGlu5 is thought to be essential for the rapid antidepressant actions of both sleep deprivation and ketamine [111]. LY341495, an antagonist of presynaptic mGlu2/3 activates VTA neuron firing via the mTOR pathway to increase dopaminergic tone [112]. LY341495 acts as a rapid-acting antidepressant in animal models of depression and is synergistic with ketamine [109, 113-115].

The $\mathrm{LHb}$ receives GABAergic inputs from the $\mathrm{VLGN//IGL}$ that are stimulated by light inputs from M4 type mRGCs, inducing antidepressive-like effects in mice [116]. As mentioned above, the LHb is involved in the circadian machinery and may play a role in antidepressant responses [33, 117-119]. This structure controls dopaminergic and serotonergic systems, integrating several brain functions, including motivation, reward and aversion, cognitive and circadian functions [34]. Interestingly, susceptible mice to stress-induced depression exhibit blunted diurnal firing within cells projecting from the LHb to the DRN [120]. Moreover, enhanced bursting in the LHb has been linked to suppression of downstream aminergic reward centers. In a rodent model of depression, ketamine inhibits the burst-type firing in the $\mathrm{LHb}$, consequently disinhibiting dopaminergic, serotonergic, and/or glutamatergic neurons of the reward system [119].

The mitogen-activated protein kinase (MAPK/ERK) pathway modulates synaptic plasticity and brain processes such as mood, learning and memory [121, 122]. Inhibition of the MAPK/ERK pathway blocks the antidepressant effects of several compounds including ketamine in mice [123]. In the mouse ACC, rapid-acting antidepressants ketamine and sleep deprivation down-regulate genes of the MAPK phosphatase family (MKPs, also known as DUSPs), which operate as the main negative regulators of MAPK signaling [124, 125]. DUSP1 undergoes fast turnover and functions in the spatiotemporal regulation of axonal organization [126]. Specifically, ketamine decreases Dusp1, Dusp5, Dusp6, and Dusp8 gene expression, while SD represses Dusp2 and Dusp27 [95]. Accordingly, whole-genome expression profiling of postmortem brain tissue, demonstrates that DUSP1 is overexpressed in subjects with MDD while preclinical studies show that that stress-induced depression in mice up-regulates Dusp1 in the ACC $[124,127,128]$. Circadian transcriptome analysis has shown that these genes, with the exception of Dusp8, are expressed in a circadian manner across tissues [95]. Importantly, DUSP1 and PER1 promoters, share the CAMP-responsive element (CRE) and the E-box element, showing similar circadian expression profiles [129]. Of relevance is that binding of BMAL1, CLOCK, and NPAS2 to their target genes is also repressed during sleep deprivation in mice [130].

The circadian system plays a contributory role in mediating synaptic plasticity via GSK3 $\beta$, a kinase that operates as a potent inhibitor of mTOR. GSK3 $\beta$ regulates multiple components of the circadian clock, including BMAL1 phosphorylation $[131,132]$ as well as modulating clock protein rhythms in the SCN $[131,133]$. Inhibition of GSK3 $\beta$ potentiates antidepressant responses to ketamine [134] in mice. GSK3 $\beta$ also regulates the circadian expression of BMAL1 in hippocampal CA1, contributing to the modulation of diurnal changes in synaptic strength or long-term potentiation (LTP) and synaptic plasticity [132]. Clinically, a specific polymorphism of GSK3 $\beta$ ( $r 334558 \mathrm{C}+$ ) has been associated with severe insomnia in patients with major depressive episode [135]. Taken together, these observations support the notion that ketamine and sleep deprivation, at least in part, commonly act via neurotransmitter systems and interestingly through the circadian clock.

\section{Circadian clock and neurogenesis}

Mechanisms of action of sustained antidepressant responses lasting one or more weeks, are thought to be attributed to processes associated with neurogenesis rather than synaptogenesis $[136,137]$. Since the half-life (t1/2) of ketamine is about $3-4 \mathrm{~h}$ [69] and the integration of newly functional neurons takes several days, it is conceivable that ketamine stimulates neurogenesis which in turn could play a role in sustained antidepressant effects [138-141]. On the other hand, given that relapse often occurs on the night following SDT, the role of neurogenesis seems less clear although bright light is capable of promoting neurogenesis [142], which could, in part, explain the long-lasting effect of the combined therapies. For example, rats exposed to bright light $(10,000$ lux, $30 \mathrm{~min} /$ day for 4 weeks) showed an increase in neurogenesis in the subgranular zone of the hippocampal dentate gyrus [142]. Conversely light deprivation in the Mongolian gerbil suppresses neurogenesis and induces depressive-like behavior [143].

Since its discovery in the 1960s, the presence of adult neurogenesis is still a matter of debate. However, growing evidence and the development of new technologies are allowing new insights of this process [144]. An in vivo imaging study confirmed that neural stem cells (NSCs) in adult mice can 
A) Circadian glio- and neuro- transmission

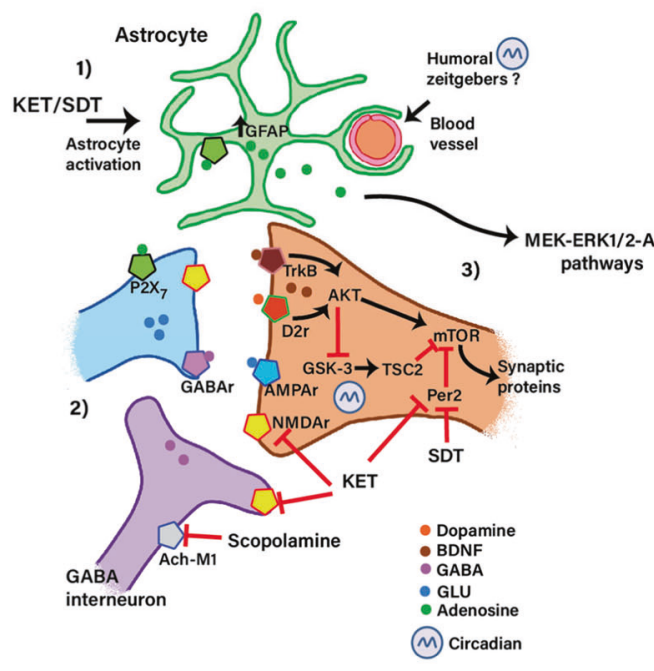

B) Key plasticity-related signaling pathways

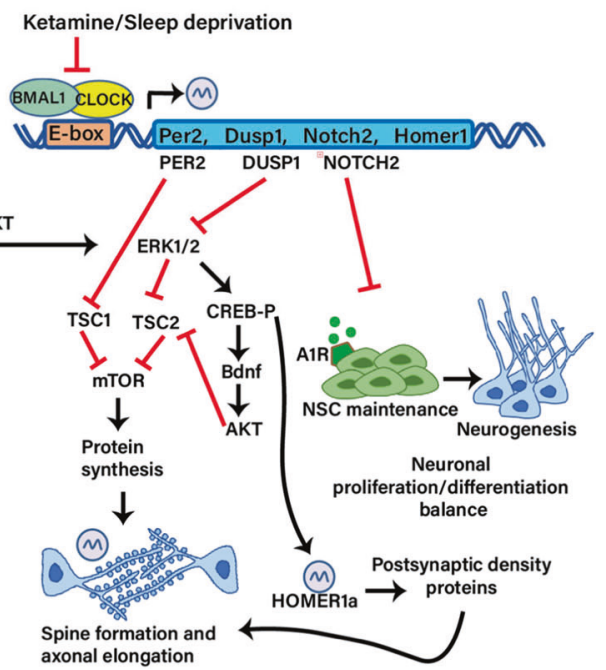

Fig. 2 Implication of the circadian clock in the regulation of neural signaling and behavior. A Proposed mechanisms of action of ketamine and sleep deprivation on the glutamatergic synapse. (1) ketamine and sleep deprivation activate astrocytes, which induces the exocytosis of adenosine, stimulating the P2 $\times 7$ (ATP-gated P2X receptor cation channel family) receptor and releasing glutamate (GLU) into the intraneuronal space. Adenosine also binds A1R in NSCs inducing its proliferation via MEK/ERK-AKT pathways [59, 166-168]. Astrocytes might further receive humoral signals acting as zeitgebers from blood vessels thereby contributing to circadian neuronal activity [170, 221]. (2) Ketamine blocks NMDA receptors at the inhibitory GABAergic interneuron, leading to disinhibition of glutamatergic transmission [75]. (3) In turn, glutamate triggers the release of BDNF at postsynaptic neurons leading to stimulation of the TrkB-AKT-mTOR and subsequent synaptic protein synthesis $[67,78,79]$. Inhibition of GSK3 $\beta$ (which is controlled by the circadian clock) contributes to the activation of mTOR [132, 222-225]. Dopamine also contributes to plasticity via the AKT-GSK3 pathway [226]. B Neuronal plasticity might be further enhanced by the inhibition (or phase-shift) of the BMAL1-CLOCK recruitment to Per2 Dusp1, Notch2, or Homer1 promoters [95]. Per2 functions as a scaffold to recruit TSC1, Raptor, and mTOR suppressing mTOR activity [227], Dusp1 negatively regulates the MAPK pathway by dephosphorylation of ERK1/2 [127]. The transcriptional reduction of Dusp1 might disinhibit ERK1/2 which in turn blocks the TSC2 complex resulting in the induction of mTOR-mediated protein synthesis. Also, ERK1/2 activates the CREB-mediated transcription of bdnf, which indirectly induces protein synthesis by blocking the TSC2 complex via AKT. The transcriptional reduction of Notch1 promotes the neurogenesis involved in neural stem cell (NSC) maintenance [159]. Homer1 transcription is further modulated by CREB and participates in the synaptic plasticity-induced by sleep deprivation and ketamine $[60,228]$. These mechanisms would be operating in different brain areas related to mood reward, and cognitive demanding tasks such as memory, attention, and decision-making such as the MPFC, hippocampus, striatum, ACC, and other brain regions.

differentiate into neurons and/or transit-amplifying progenitors, which in fact are capable of self-renewing and differentiating into neurons [145].

Several brain alterations have been related to neurogenesis. Reduced hippocampal neurogenesis is associated with psychiatric disease including schizophrenia and depression [140, 146-148]. Moreover, monoaminergic or glutamatergic antidepressants show significant effects on neurogenesis [140, 149].

The role of the circadian clock in the homeostasis of stem cells and in the regulation of cellular development including differentiation across tissue subtypes is supported by a number of studies [150-153]. Decreased BMAL1 in mice shows deficits in cognition [151, 154]. Reduced Cry2 expression in the DG of adult mice is also associated with behavioral disorders of anxiety and depressive-like behavior [154]. The circadian clock has been implicated in controlling the expression of key regulators of neurodevelopment to help synchronize the differentiation of heterogeneous populations of cells. The signaling molecules within the NOTCH pathway, an important component of the neurodevelopmental signaling process [155], are under circadian clock control [156-158]. Interestingly both ketamine and SD alter the expression levels of transcripts of genes in the NOTCH pathway (Fig. 2B), particularly in the ACC of sleep deprivation- and ketamine-treated mice where Notch2 expression is reduced [95]. Importantly, as NOTCH2 preserves a state of latency on NSCs, its loss of function induces proliferation and increases neurogenesis in the hippocampus [159], as well as neuronal differentiation in NSC progenitors [160]. Moreover, the Notch2 gene is expressed in a circadian manner and contains an E-box within its promoter
[157]. Therefore, ketamine and SD would modulate neurogenesis by regulating the circadian expression of NOTCH pathway components. Accordingly, one night of SD in healthy human male subjects leads to epigenetic modifications in components of the NOTCH pathway, as observed in blood samples of the subjects [161].

Another circuitry of interest as mentioned above is the TrkBdependent induction of the ERK pathway. It is hypothesized that ketamine could induce antidepressant effects through its enhancement of hippocampal neurogenesis acting via the ERK pathway and its components [138]. Supporting this hypothesis, ketamine increases neurogenesis in the dentate gyrus and in ventral hippocampus in both acute and chronically stressed mice, which can lead to depressive-like behavior. This was accompanied by an induction of GluN2B subunit of NMDAR, GluA1 subunit of AMPAR, as well as phosphorylation of mTOR [162, 163]. Likewise, sleep deprivation ( $12 \mathrm{~h}$ sleep deprivation in rodents) was shown to increase neurogenesis in the hippocampus $[164,165]$ and increase the levels of BDNF [96].

Further, the activation of the adenosine receptors $A 1 R$ and $A 2 B$ expressed in NSC, induce stem cell proliferation acting on MEK/ ERK-AKT pathways [166]. Astrocytes participate in the antidepressant effects of both ketamine and SD in mice [59, 167, 168]. Ketamine, in a chronic unpredictable stress model in rats, acts on astrocytes by modulating glutamate transporter 1 (GLT1) expression, consequently increasing astrocyte plasticity via the BDNF-TrkB pathways and concomitantly decreasing apoptosis of astrocytes [169]. Importantly, evidence suggests that astrocytes, as a part of the neurovascular system [170], are capable of 
computing peripheral signals and consequently receiving information from internal and external zeitgebers through their internal clocks, which then allows them to respond by modulating neuronal functions (Fig. 2A). Future studies may provide further details on the contributions of the astrocytic molecular clock on brain circadian synchronization/deregulation related to MDD.

\section{Additional issues relevant to mood disorders, pathophysiology, and treatment}

Circadian versus non-circadian factors underlying rapid antidepressant effects. Although this review focuses primarily on the circadian interactions involving ketamine and SDT, non-circadian factors are also considered important contributors to the acceleration of antidepressant actions. For example, subanesthetic ketamine alters the distribution of cholesterol within astrocytes resulting in the modulation of downstream glutamatergic processes thought to be important to ketamine's antidepressant effects (e.g., NMDA, AMPA, and mTOR [171]). Likewise, Reelin signaling has attracted attention as a putative mechanism of action of ketamine. In mice, genetic deletion of Reelin, a glycoprotein, was shown to block both ketaminemediated depressive-like behavior and synaptic potentiation via modulation of the basal activity of the NMDA receptor [172]. Finally, micro-RNAs (mi-RNAs) in postmortem brains of MDDs and BP patients are reported to be down-regulated [173]. The importance of mi-RNAs is that they can exert a broad range of effects by binding to hundreds of target genes including those regulating synaptogenesis and neurotransmitters. Evidence that ketamine may exert its antidepressant actions via mi-RNAs comes from a study in a mouse model of depressive-like behavior whereby ketamine reversed the downregulation of miR-98-5p in the hippocampus and prefrontal cortex, while an antagonist of miR-98-5 blocked ketamine's antidepressant effects [174].

Conventional antidepressants share mechanisms of action with ketamine and sleep deprivation but have a delayed response. Traditional antidepressants and anti-manic compounds (e.g., lithium, valproic acid) share overlapping mechanisms with ketamine and sleep deprivation by promoting neurogenesis and synaptic plasticity [11, 175-178]. In animal models of depression, antidepressant effects of ketamine and SDT can take place in a matter of minutes to hours $[104,105,179]$. It is not yet known whether other classes of antidepressants promote neurogenesis within a similar time-frame. Further, it might be predicted that melatonin agonizts would have antidepressant properties as they phase-shift circadian rhythms and elicit depressive-like effects in mice. However, clinical data do not support melatonin as effective $[180,181]$ although the reason(s) for the lack of clinical response is not known.

Circadian interventions can decrease switches into hypomania/ mania in BP following SDT. A relatively small percentage of bipolar patients are at risk for switches into hypomania $(5.83 \%)$ and mania (4.85\%) following SDT, comparable to the rate of switches associated with other classes of antidepressants [182]. Two strategies for decreasing switches is to administer bright light therapy following SDT in mid-day rather than early morning [183] and second, to block blue light [184]. It is suggested that mid-day bright light has a weaker effect on phase advancing melatonin rhythms than morning bright light $[185,186]$. Blocking blue light (wavelength 400-500 nm associated with daylight, dampens ipRGCs signals [187]. Indeed, randomized placebo-controlled trials showed that blue-blocking sunglasses significantly decreased the incidence of switches [184, 188].

Relationship between circadian phase-specific phenotype and efficacy of rapid-acting antidepressants. To date, there is no consistent answer as to whether "circadian phase-specific" phenotypes show greater efficacy to fast-acting antidepressants
[21]. Although ketamine phase advances activity rhythms in ketamine responders, it is premature to infer that responders are phase-delayed [189]. There is much to be learned by measuring circadian parameters (e.g., rhythmic changes in metabolites, gene expression, activity, sleep, core body temperature, mood) as well as from questionnaires (e.g., Morningness-Eveningness (MEQ), Munich Chronotype (MCTQ)] to help clarify whether altered chronotypes are an essential factor in the therapeutic response to rapid-acting antidepressants. Predictive models incorporating circadian factors, as seen with ketamine, for example, could provide important insights [190]. Advances in machine learning offer unique opportunities to identify key variables relevant to treatment outcomes [191-193].

Altered circadian rhythms in responders vs. non-responders to ketamine and SDT. To date, identification of biological signatures and circadian patterns associated with response to rapid antidepressants is not yet known. To our knowledge there are no studies that address the efficacy of ketamine nor SDT as a function of circadian phenotypes (i.e., delayed or advanced rhythms, shorter or longer periods). Treatment-resistant depression (failure to respond to two or more traditional antidepressants) may define a particular circadian phenotype. The same may also be true for sleep deprivation responders although more research is needed. Moreover, there is little data differentiating circadian phenotypes of MDD and bipolar patients in terms of response to ketamine or SDT. More research is needed to further identify the circadian variables affecting biological rhythms.

Genome-wide association studies (GWAS). GWAS studies have identified variations in circadian rhythm phenotypes associated with either bipolar or MDD [194, 195]. In BP, none of the canonical clock genes were overrepresented [196]. In contrast, a GWAS study of rapid-cycling BP patients (European Americans and African Americans) showed SNP-based heritability and identified the SNP rs683813 (mapped closed to BMAL2 (a paralog of BMAL1)) [197]. Data in MDD showed an association at the genome-wide levels for CRY1 (rs2287161), NPAS2 (rs11123857) with the strongest association in a SNP located near the CRY1 gene [198]. Additional molecular evidence from GWAS studies for circadian abnormalities is supported by genetic and transcriptomic data showing an association between circadian gene polymorphisms and MDD. These include CRY2 (rs10838524), VIPR2 (rs885861), TEF (rs738499), and SIRT1 (rs10997875) [22, 23, 198, 199]. Moreover, carriers of the CRY1 (rs2287161), NPAS2 (rs11123857), and VIPR2 (rs885861) SNPs are three times more likely to suffer from MDD [198].

Mechanistic links between the circadian clock and MDD: key strategies. Homeostasis requires an integration of circadian signaling across cells, tissues and organs achieved through direct and indirect transcriptional processes. Though the core-clock genes are ubiquitously rhythmic, transcripts are tissue-specific to biological processes [200]. In cortex, synaptic structure and function is driven by two waves of daily oscillations in synchrony with the sleep-wake cycle. Transcriptomic analyses of mouse forebrain synaptoneurosomes showed that transcripts and proteins accumulate in anticipation of the rodent active phase (dark) whereas mRNAs associated with metabolism, intracellular signaling and translation precede the resting phase (light). When sleep pressure is high as with sleep deprivation a major portion of the circadian proteome is eradicated [201]. In parallel, loss of sleep, dynamically induces a dampening of synaptic strength in forebrain via phosphorylation [202]. Taken together, these studies provide further support for a role of cortical synaptic remodeling as a mode of action for the antidepressant effects of sleep deprivation. As reviewed above, ketamine can induce rapid changes in synaptic remodeling, possibly through glutamatergic 
interactions [81, 103, 106, 111]. A strategy would be to stabilize the modifications in synaptic remodeling with additional treatments to prolong the antidepressant responses associated with rapid-acting antidepressants. To our knowledge there are no studies that have applied bright light therapy and sleep phase advance to ketamine responders. Additionally, it is not known whether administration of subanesthetic ketamine would help stabilize responses to SDT. If these two interventions converge on similar synaptogenic signaling pathways, the combined effect might help sustain improvement beyond weeks to months.

Rhythmic signals from single cells to synchronization of tissue involve the coupling of period and phase between individual oscillators. The coupling of cellular oscillators ("tissue clock") with tissue oscillators comprise an organismal clock $[39,203]$ that is essential to maintaining physiological homeostasis. This also encompasses entrainment to intrinsic and extrinsic signaling (e.g., neurotransmitters, metabolites, nutrients, humoral, and environmental factors [39-41]. This can be achieved by multiple molecular regulatory systems including circadian control on mi-RNAs [204], epigenetic chromatin remodeling [205], transcriptional [206], posttranscriptional [200], translational, and posttranslational modifications that impinge at cellular, tissue, and system levels. Especially advantageous are the "omic" technologies (e.g., transcriptomics, proteomics, metabolomics) [207], which are currently being applied to circadian research [200, 208-210]. Studies of the circadian proteome have helped to characterize rhythmic signaling pathways [211]. Thus, analyzing the circadian variations (acrophase, amplitude and mesor) and their effects on various biological processes, could help identify processes linking the circadian clock to rapid-acting antidepressants. Additionally, they could provide insight to understand how rapid-acting antidepressants can modulate those rhythmic processes involved to mood regulation at molecular, cellular, physiological and behavioral levels (Fig. 1B). The integration of several lines of research could help identify a biological signature to evaluate homeostasis and to assist clinicians in determining optimal treatments.

Gender-relevant circadian phenotypes. An estimated $20-30 \%$ of MDD patients are hypothesized to have a "circadian rhythm depression" disorder. Gender differences in this subgroup show that females have shorter intrinsic circadian periods and higher plasma melatonin and cortisol levels [212]. Gender differences were also identified in postmortem nonpsychiatric brain tissue showing that males had almost twice as many significant rhythmic transcripts in the DLPFC while females had nearly four times as many rhythmic transcripts in the anterior cingulate (ACC) [213]. The significance of these findings is not yet known although gender-specific machine learning models are being applied to predict responses to SSRI classes of antidepressants [214].

\section{CONCLUDING REMARKS}

Despite the widespread use of traditional antidepressants, suicide rates in the US have significantly increased from 30,000 to 46,000 deaths per year from 1999 to 2017 [215] and increased to 48,344 in 2020 [216], reflecting the limitations of monoaminergic-based treatments. Epidemiological, clinical and experimental evidence over the past 50 years has clearly established a causal link between circadian disruptions including sleep disturbances, hormonal secretions, core body temperature and mood in a subset of MDD and BPD patients [6, 8-13]. This coincides with modern lifestyle "social zeitgebers" which are frequently associated with sleep disorders, increased stress, and circadian disruptions $[27,217]$. Considering that maladaptation to the environment may increase the risk for psychiatric disorders [218], it is conceivable that these disorders could be associated with circadian desynchronization affecting high brain function and mood [25]. The antidepressant actions of non-pharmacological chronotherapies such as bright light therapy, sleep phase advance, and SDT support a circadian hypothesis as do emerging findings on the modulation of the circadian clock and its pathways by the pharmacological actions of ketamine (Fig. 2) [94, 95, 219]. It is not yet known whether depressed patients with dysregulated circadian rhythms are more likely to respond to fast-acting antidepressants such as ketamine or to SDT.

A limitation to the circadian hypothesis is that there are no definitive genes and/or pathways that are known to be directly correlated with a rapid response to sleep deprivation or to ketamine. Rather, most of the data is inferred, based upon a relatively large number of studies in rodent models of depressivelike behavior that are predominantly focused on ketamine and less so, on sleep deprivation. The animal data and clinical observations should motivate researchers to continue to obtain information relevant to this investigative area. Finally, this is an exciting time for the scientific community to understand in greater depth the pathophysiological basis of depressive illness and to consequently, improve prophylactic and therapeutic treatments.

\section{REFERENCES}

1. WHO. World Health Organization, facts sheets: depression. 2021 (https://www. who.int/news-room/fact-sheets/detail/depression). Accesed 15 Jan 2021.

2. Krishnan V, Nestler EJ. Linking molecules to mood: new insight into the biology of depression. Am J Psychiatry. 2010;167:1305-20.

3. WHO. World Health Organization: suicide data. 2021 (http://www.who.int/ mediacentre/factsheets/fs398/en/). Accesed 15 Jan 2021.

4. Proudman D, Greenberg $P$, Nellesen D. The growing burden of major depressive disorders (MDD): implications for researchers and policy makers. Pharmacoeconomics. 2021;39:619-25.

5. Benedetti F, Riccaboni R, Locatelli C, Poletti S, Dallaspezia S, Colombo C. Rapid treatment response of suicidal symptoms to lithium, sleep deprivation, and light therapy (chronotherapeutics) in drug-resistant bipolar depression. J Clin Psychiatry. 2014;75:133-40.

6. Bunney BG, Li JZ, Walsh DM, Stein R, Vawter MP, Cartagena P, et al. Circadian dysregulation of clock genes: clues to rapid treatments in major depressive disorder. Mol Psychiatry. 2015;20:48-55.

7. Pereira VS, Hiroaki-Sato VA. A brief history of antidepressant drug development: from tricyclics to beyond ketamine. Acta Neuropsychiatr. 2018;30:307-22.

8. Bernert RA, Kim JS, Iwata NG, Perlis ML. Sleep disturbances as an evidencebased suicide risk factor. Curr Psychiatry Rep. 2015;17:15.

9. Logan RW, McClung CA. Rhythms of life: circadian disruption and brain disorders across the lifespan. Nat Rev Neurosci. 2019;20:49-65.

10. Wulff K, Gatti S, Wettstein JG, Foster RG. Sleep and circadian rhythm disruption in psychiatric and neurodegenerative disease. Nat Rev Neurosci. 2010;11:589.

11. Moon JH, Cho CH, Son GH, Geum D, Chung S, Kim H, et al. Advanced circadian phase in mania and delayed circadian phase in mixed mania and depression returned to normal after treatment of bipolar disorder. EBioMedicine. 2016;11:285-95.

12. Hasler BP, Buysse DJ, Kupfer DJ, Germain A. Phase relationships between core body temperature, melatonin, and sleep are associated with depression severity: further evidence for circadian misalignment in non-seasonal depression. Psychiatry Res. 2010;178:205-7.

13. Lyall LM, Wyse CA, Graham N, Ferguson A, Lyall DM, Cullen B, et al. Association of disrupted circadian rhythmicity with mood disorders, subjective wellbeing, and cognitive function: a cross-sectional study of 91105 participants from the UK Biobank. Lancet Psychiatry. 2018;5:507-14.

14. Chellappa SL, Morris CJ, Scheer FA. Circadian misalignment increases mood vulnerability in simulated shift work. Sci Rep. 2020;10:1-10.

15. Li JZ, Bunney BG, Meng F, Hagenauer MH, Walsh DM, Vawter MP, et al. Circadian patterns of gene expression in the human brain and disruption in major depressive disorder. Proc Natl Acad Sci USA. 2013;110:9950-5.

16. Brancaccio M, Edwards MD, Patton AP, Smyllie NJ, Chesham JE, Maywood ES, et al. Cell-autonomous clock of astrocytes drives circadian behavior in mammals. Science. 2019;363:187-92.

17. Gerstner JR, Yin JCP. Circadian rhythms and memory formation. Nat Rev Neurosci. 2010;11:577-88.

18. Valdez P. Circadian rhythms in attention. Yale J Biol Med. 2019;92:81-92.

19. Musiek ES, Holtzman DM. Mechanisms linking circadian clocks, sleep, and neurodegeneration. Science. 2016;354:1004-08. 
20. Orozco-Solis R, Aguilar-Arnal L, Murakami M, Peruquetti R, Ramadori G, Coppari $\mathrm{R}$, et al. The circadian clock in the ventromedial hypothalamus controls cyclic energy expenditure. Cell Metab. 2016;23:467-78.

21. Geoffroy PA, Palagini L. Biological rhythms and chronotherapeutics in depression. Prog Neuropsychopharmacol Biol Psychiatry. 2021;106:110158.

22. Charrier A, Olliac B, Roubertoux $P$, Tordjman S. Clock genes and altered sleepwake rhythms: their role in the development of psychiatric disorders. Int J Mol Sci. 2017;18:938-59.

23. Wray NR, Ripke S, Mattheisen M, Trzaskowski M, Byrne EM, Abdellaoui A, et al. Genome-wide association analyses identify 44 risk variants and refine the genetic architecture of major depression. Nat Genet. 2018;50:668-81.

24. Mukherjee S, Coque L, Cao J-L, Kumar J, Chakravarty S, Asaithamby A, et al. Knockdown of clock in the ventral tegmental area through RNA interference results in a mixed state of mania and depression-like behavior. Biol Psychiatry. 2010;68:503-11.

25. Landgraf D, Long JE, Proulx CD, Barandas R, Malinow R, Welsh DK. Genetic disruption of circadian rhythms in the suprachiasmatic nucleus causes helplessness, behavioral despair, and anxiety-like behavior in mice. Biol Psychiatry. 2016:80:827-35.

26. Logan RW, Edgar N, Gillman AG, Hoffman D, Zhu X, McClung CA. Chronic stress induces brain region-specific alterations of molecular rhythms that correlate with depression-like behavior in mice. Biol Psychiatry. 2015;78:249-58.

27. Orozco-Solis R, Sassone-Corsi P. Epigenetic control and the circadian clock: Linking metabolism to neuronal responses. Neuroscience. 2014;264:76-87.

28. Morin LP. Neuroanatomy of the extended circadian rhythm system. Exp Neurol. 2013:243:4-20.

29. Moga MM, Moore RY. Organization of neural inputs to the suprachiasmatic nucleus in the rat. J Comp Neurol. 1997;389:508-34.

30. Sylvester CM, Krout KE, Loewy AD. Suprachiasmatic nucleus projection to the medial prefrontal cortex: a viral transneuronal tracing study. Neuroscience. 2002;114:1071-80.

31. Fernandez DC, Fogerson PM, Lazzerini Ospri L, Thomsen MB, Layne RM, Severin $D$, et al. Light affects mood and learning through distinct retina-brain pathways. Cell. 2018;175:71-84.e18.

32. Mendoza J. Circadian neurons in the lateral habenula: clocking motivated behaviors. Pharmacol Biochem Behav. 2017;162:55-61.

33. Bano-Otalora B, Piggins HD. Contributions of the lateral habenula to circadian timekeeping. Pharmacol Biochem Behav. 2017;162:46-54.

34. Hu H, Cui Y, Yang Y. Circuits and functions of the lateral habenula in health and in disease. Nat Rev Neurosci. 2020;21:277-95.

35. Salaberry NL, Hamm H, Felder-Schmittbuhl MP, Mendoza J. A suprachiasmaticindependent circadian $\operatorname{clock}(\mathrm{s})$ in the habenula is affected by Per gene mutations and housing light conditions in mice. Brain Struct Funct. 2019;224:19-31.

36. Olejniczak I, Ripperger JA, Sandrelli F, Schnell A, Mansencal-Strittmatter L, Wendrich $\mathrm{K}$, et al. Light affects behavioral despair involving the clock gene Period 1. PLoS Genet. 2021;17:e1009625.

37. Aguilar-Arnal L, Sassone-Corsi P. The circadian epigenome: how metabolism talks to chromatin remodeling. Curr Opin Cell Biol. 2013;25:170-6.

38. Eckel-Mahan KL, Patel VR, de Mateo S, Orozco-Solis R, Ceglia NJ, Sahar S, et al. Reprogramming of the circadian clock by nutritional challenge. Cell. 2013:155:1464-78.

39. Koronowski KB, Sassone-Corsi P. Communicating clocks shape circadian homeostasis. Science. 2021;371:eabd0951.

40. Astiz M, Heyde I, Oster H. Mechanisms of communication in the mammalian circadian timing system. Int J Mol Sci. 2019;20:343.

41. Bass J, Lazar MA. Circadian time signatures of fitness and disease. Science. 2016;354:994-9.

42. Greco CM, Sassone-Corsi P. Circadian blueprint of metabolic pathways in the brain. Nat Rev Neurosci. 2019;20:71-82.

43. LeGates TA, Fernandez DC, Hattar S. Light as a central modulator of circadian rhythms, sleep and affect. Nat Rev Neurosci. 2014;15:443-54.

44. Zaki NFW, Spence DW, BaHammam AS, Pandi-Perumal SR, Cardinali DP, Brown GM. Chronobiological theories of mood disorder. Eur Arch Psychiatry Clin Neurosci. 2018;268:107-18.

45. Sato S, Sassone-Corsi P. Circadian and epigenetic control of depression-like behaviors. Curr Opin Behav Sci. 2019;25:15-22.

46. Gottlieb JF, Goel N, Chen S, Young MA. Meta-analysis of sleep deprivation in the acute treatment of bipolar depression. Acta Psychiatr Scand. 2021;143:319-27.

47. Wu JC, Bunney WE. The biological basis of an antidepressant response to sleep deprivation and relapse: review and hypothesis. Am J Psychiatry. 1990;147:14-21.

48. Winkler D, Spies M, Al-Resheg Y, Wu JC, Bunney WE, Bunney BG, et al. Usage of therapeutic sleep deprivation: a survey in psychiatric hospitals in Austria, Germany, and Switzerland. Behav Sleep Med. 2019;17:713-20.
49. Wu JC, Kelsoe JR, Schachat C, Bunney BG, DeModena A, Golshan S, et al. Rapid and sustained antidepressant response with sleep deprivation and chronotherapy in bipolar disorder. Biol Psychiatry. 2009;66:298-301.

50. D'Agostino A, Ferrara P, Terzoni S, Ostinelli EG, Carrara C, Prunas C, et al. Efficacy of triple chronotherapy in unipolar and bipolar depression: a systematic review of the available evidence. J Affect Disord. 2020;276:297-304.

51. Cirelli C, Tononi G. The why and how of sleep-dependent synaptic downselection. Semin Cell Dev Biol. 2021:In Press.

52. Tononi G, Cirelli C. Sleep and the price of plasticity: from synaptic and cellular homeostasis to memory consolidation and integration. Neuron. 2014;81:12-34.

53. Raven F, Van der Zee EA, Meerlo P, Havekes R. The role of sleep in regulating structural plasticity and synaptic strength: Implications for memory and cognitive function. Sleep Med Rev. 2018;39:3-11.

54. Benedetti F, Colombo C, Serretti A, Lorenzi C, Pontiggia A, Barbini B, et al. Antidepressant effects of light therapy combined with sleep deprivation are influenced by a functional polymorphism within the promoter of the serotonin transporter gene. Biol Psychiatry. 2003;54:687-92.

55. Benedetti F, Barbini B, Bernasconi A, Fulgosi MC, Colombo C, Dallaspezia S, et al. Serotonin 5-HT2A receptor gene variants influence antidepressant response to repeated total sleep deprivation in bipolar depression. Prog Neuropsychopharmacol Biol Psychiatry. 2008;32:1863-6.

56. Benedetti F, Serretti A, Colombo C, Lorenzi C, Tubazio V, Smeraldi E. A glycogen synthase kinase 3-beta promoter gene single nucleotide polymorphism is associated with age at onset and response to total sleep deprivation in bipolar depression. Neurosci Lett. 2004;368:123-6.

57. Dallaspezia S, Locatelli C, Lorenzi C, Pirovano A, Colombo C, Benedetti F. Sleep homeostatic pressure and PER3 VNTR gene polymorphism influence antidepressant response to sleep deprivation in bipolar depression. J Affect Disord. 2016;192:64-9.

58. Foo JC, Trautmann N, Sticht C, Treutlein J, Frank J, Streit F, et al. Longitudinal transcriptome-wide gene expression analysis of sleep deprivation treatment shows involvement of circadian genes and immune pathways. Transl Psychiatry. 2019;9:343.

59. Hines DJ, Schmitt LI, Hines RM, Moss SJ, Haydon PG. Antidepressant effects of sleep deprivation require astrocyte-dependent adenosine mediated signaling. Transl Psychiatry. 2013;3:e212.

60. Serchov T, Clement H-W, Schwarz Martin K, lasevoli F, Tosh DK, Idzko M, et al. Increased signaling via adenosine A1 receptors, sleep deprivation, imipramine, and ketamine inhibit depressive-like behavior via induction of Homer1a. Neuron. 2015;87:549-62.

61. Halassa MM, Florian C, Fellin T, Munoz JR, Lee SY, Abel T, et al. Astrocytic modulation of sleep homeostasis and cognitive consequences of sleep loss. Neuron. 2009;61:213-9.

62. Pascual O, Casper KB, Kubera C, Zhang J, Revilla-Sanchez R, Sul J-Y, et al. Astrocytic purinergic signaling coordinates synaptic networks. Science. 2005;310:113-16

63. Haydon PG. Astrocytes and the modulation of sleep. Curr Opin Neurobiol. 2017;44:28-33.

64. Brancaccio M, Patton AP, Chesham JE, Maywood ES, Hastings MH. Astrocytes control circadian timekeeping in the suprachiasmatic nucleus via glutamatergic signaling. Neuron. 2017;93:1420-35.e5.

65. Broadhead MJ, Miles GB. A common role for astrocytes in rhythmic behaviours? Prog Neurobiol. 2021;202:102052.

66. Morgan PT. Ketamine and sleep: bridging the gap in the treatment of depressive illness. Biol Psychiatry. 2017;82:309-11.

67. Abdallah CG, Adams TG, Kelmendi B, Esterlis I, Sanacora G, Krystal JH. Ketamine's mechanism of action: a path to rapid-acting antidepressants. Depress Anxiety. 2016;33:689-97.

68. Zanos P, Moaddel R, Morris PJ, Georgiou P, Fischell J, Elmer Gl, et al. NMDAR inhibition-independent antidepressant actions of ketamine metabolites. Nature. 2016;533:481-6.

69. Memon RI, Naveed S, Faquih AE, Fida A, Abbas N, Chaudhary AMD, et al. Effectiveness and safety of ketamine for unipolar depression: a systematic review. Psychiatr Q. 2020;91:1147-92.

70. Phillips JL, Norris S, Talbot J, Birmingham M, Hatchard T, Ortiz A, et al. Single, repeated, and maintenance ketamine infusions for treatment-resistant depression: a randomized controlled trial. Am J Psychiatry. 2019;176:401-9.

71. Altinay $M$, Karne $H$, Anand A. Administration of sub-anesthetic dose of ketamine and electroconvulsive treatment on alternate week days in patients with treatment resistant depression: a double blind placebo controlled trial. Psychopharmacol Bull. 2019;49:8-16.

72. Grunebaum MF, Galfalvy HC, Choo TH, Keilp JG, Moitra VK, Parris MS, et al. Ketamine for rapid reduction of suicidal thoughts in major depression: a midazolam-controlled randomized clinical trial. Am J Psychiatry. 2018;175:327-35. 
73. Siegel AN, Di Vincenzo JD, Brietzke E, Gill H, Rodrigues NB, Lui LMW, et al. Antisuicidal and antidepressant effects of ketamine and esketamine in patients with baseline suicidality: a systematic review. J Psychiatr Res. 2021;137:426-36.

74. Gastaldon C, Raschi E, Kane JM, Barbui C, Schoretsanitis G. Post-marketing safety concerns with esketamine: a disproportionality analysis of spontaneous reports submitted to the FDA adverse event reporting system. Psychother Psychosom. 2021;90:41-8.

75. Gerhard DM, Pothula S, Liu R-J, Wu M, Li X-Y, Girgenti MJ, et al. GABA interneurons are the cellular trigger for ketamine's rapid antidepressant actions. J Clin Investig. 2020;130:1336-49.

76. Krystal JH, Abdallah CG, Sanacora G, Charney DS, Duman RS. Ketamine: a paradigm shift for depression research and treatment. Neuron. 2019;101:774-8.

77. Zanos P, Gould TD. Mechanisms of ketamine action as an antidepressant. Mol Psychiatry. 2018;23:801-11.

78. Kadriu B, Musazzi L, Henter ID, Graves M, Popoli M, Zarate CA Jr. Glutamatergic neurotransmission: pathway to developing novel rapid-acting antidepressant treatments. Int J Neuropsychopharmacol. 2019;22:119-35.

79. Duman RS, Aghajanian GK, Sanacora G, Krystal JH. Synaptic plasticity and depression: new insights from stress and rapid-acting antidepressants. Nat Med. 2016;22:238-49.

80. Maeng S, Zarate CA Jr., Du J, Schloesser RJ, McCammon J, Chen G, et al. Cellular mechanisms underlying the antidepressant effects of ketamine: role of alphaamino-3-hydroxy-5-methylisoxazole-4-propionic acid receptors. Biol Psychiatry. 2008;63:349-52

81. Li N, Lee B, Liu RJ, Banasr M, Dwyer JM, Iwata M, et al. mTOR-dependent synapse formation underlies the rapid antidepressant effects of NMDA antagonists. Science. 2010;329:959-64.

82. Liu R-J, Lee FS, Li X-Y, Bambico F, Duman RS, Aghajanian GK. Brain-derived neurotrophic factor Val66Met allele impairs basal and ketamine-stimulated synaptogenesis in prefrontal cortex. Biol Psychiatry. 2012;71:996-1005.

83. Autry AE, Adachi M, Nosyreva E, Na ES, Los MF, Cheng P-f, et al. NMDA receptor blockade at rest triggers rapid behavioural antidepressant responses. Nature. 2011;475:91-5

84. Chang S-w, Yoshihara T, Machida S, Naito H. Circadian rhythm of intracellular protein synthesis signaling in rat cardiac and skeletal muscles. Biochem Biophysics Rep. 2017;9:153-8.

85. Cao R, Gkogkas CG, de Zavalia N, Blum ID, Yanagiya A, Tsukumo Y, et al. Lightregulated translational control of circadian behavior by elF4E phosphorylation. Nat Neurosci. 2015;18:855.

86. Cao R. mTOR signaling, translational control, and the circadian clock. Front Genet. 2018;9:367.

87. Lipton Jonathan O, Yuan Elizabeth D, Boyle Lara M, Ebrahimi-Fakhari D Kwiatkowski $E$, Nathan $A$, et al. The circadian protein BMAL1 regulates translation in response to S6K1-mediated phosphorylation. Cell. 2015;161:1138-51.

88. Casarotto PC, Girych M, Fred SM, Kovaleva V, Moliner R, Enkavi G, et al. Antidepressant drugs act by directly binding to TRKB neurotrophin receptors. Cell. 2021;184:1299-313.e19.

89. Coria-Lucero CD, Golini RS, Ponce IT, Deyurka N, Anzulovich AC, Delgado SM et al. Rhythmic Bdnf and TrkB expression patterns in the prefrontal cortex are lost in aged rats. Brain Res. 2016;1653:51-8.

90. Jang S-W, Liu X, Pradoldej S, Tosini G, Chang Q, luvone PM, et al. $\mathrm{N}$-acetylserotonin activates TrkB receptor in a circadian rhythm. Proc Natl Acad Sci. 2010;107:3876-81.

91. Nobis A, Zalewski D, Waszkiewicz N. Peripheral markers of depression. J Clin Med. 2020;9:3793-846.

92. Stenovec M, Li B, Verkhratsky A, Zorec R. Astrocytes in rapid ketamine antidepressant action. Neuropharmacology. 2020;173:108158.

93. Schroor MM, Sennels HP, Fahrenkrug J, Jorgensen HL, Plat J, Mensink RP. Diurnal variation of markers for cholesterol synthesis, cholesterol absorption, and bile acid synthesis: a systematic review and the bispebjerg study of diurnal variations. Nutrients. 2019;11:1439-59.

94. Bellet MM, Vawter MP, Bunney BG, Bunney WE, Sassone-Corsi P. Ketamine influences CLOCK:BMAL1 function leading to altered circadian gene expression. PLOS ONE. 2011;6:e23982.

95. Orozco-Solis R, Montellier E, Aguilar-Arnal L, Sato S, Vawter MP, Bunney BG, et al. A circadian genomic signature common to ketamine and sleep deprivation in the anterior cingulate cortex. Biol Psychiatry. 2017;82:351-60.

96. Cheng O, Li R, Zhao L, Yu L, Yang B, Wang J, et al. Short-term sleep deprivation stimulates hippocampal neurogenesis in rats following global cerebral ischemia/reperfusion. PloS ONE. 2015;10:e0125877.

97. Conti B, Maier R, Barr AM, Morale MC, Lu X, Sanna PP, et al. Region-specific transcriptional changes following the three antidepressant treatments electro convulsive therapy, sleep deprivation and fluoxetine. Mol Psychiatry. 2007;12:167-89.
98. Cirelli C, Tononi G. Differential expression of plasticity-related genes in waking and sleep and their regulation by the noradrenergic system. J Neurosci. 2000;20:9187-94.

99. Liang FQ, Allen G, Earnest D. Role of brain-derived neurotrophic factor in the circadian regulation of the suprachiasmatic pacemaker by light. J Neurosci. 2000;20:2978-87.

100. Colwell CS. Linking neural activity and molecular oscillations in the SCN. Nat Rev Neurosci. 2011;12:553-69.

101. Zhou Z, Hong EJ, Cohen S, Zhao W-n, Ho H-yH, Schmidt L, et al. Brain-specific phosphorylation of MeCP2 regulates activity-dependent Bdnf transcription, dendritic growth, and spine maturation. Neuron. 2006;52:255-69.

102. Lei T, Dong D, Song M, Sun Y, Liu X, Zhao H. Rislenemdaz treatment in the lateral habenula improves despair-like behavior in mice. Neuropsychopharmacology. 2020;45:1717-24.

103. Zhang J, Qu Y, Chang L, Pu Y, Hashimoto K. (R)-Ketamine rapidly ameliorates the decreased spine density in the medial prefrontal cortex and hippocampus of susceptible mice after chronic social defeat stress. Int J Neuropsychopharmacol. 2019;22:675-9.

104. Gisabella B, Scammell T, Bandaru SS, Saper CB. Regulation of hippocampal dendritic spines following sleep deprivation. J Comp Neurol. 2020;528:380-8.

105. Spano GM, Banningh SW, Marshall W, de Vivo L, Bellesi M, Loschky SS, et al. Sleep deprivation by exposure to novel objects increases synapse density and axon-spine interface in the hippocampal CA1 region of adolescent mice. J Neurosci. 2019;39:6613-25.

106. Kavalali ET, Monteggia LM. Targeting homeostatic synaptic plasticity for treatment of mood disorders. Neuron. 2020;106:715-26.

107. Tomasetti C, lasevoli F, Buonaguro EF, De Berardis D, Fornaro M, Fiengo ALC, et al. Treating the synapse in major psychiatric disorders: the role of postsynaptic density network in dopamine-glutamate interplay and psychopharmacologic drugs molecular actions. Int J Mol Sci. 2017;18:135.

108. Gujar N, Yoo SS, Hu P, Walker MP. Sleep deprivation amplifies reactivity of brain reward networks, biasing the appraisal of positive emotional experiences. J Neurosci. 2011;31:4466-74.

109. Witkin JM, Monn JA, Schoepp DD, Li X, Overshiner C, Mitchell SN, et al. The rapidly acting antidepressant ketamine and the mGlu2/3 receptor antagonist LY341495 rapidly engage dopaminergic mood circuits. J Pharmacol Exp Ther. 2016:358:71-82

110. Pilc A, Chaki S, Nowak G, Witkin JM. Mood disorders: regulation by metabotropic glutamate receptors. Biochem Pharmacol. 2008;75:997-1006.

111. Holz A, Mulsch F, Schwarz MK, Hollmann M, Dobrossy MD, Coenen VA, et al. Enhanced mGlu5 signaling in excitatory neurons promotes rapid antidepressant effects via AMPA receptor activation. Neuron. 2019;104:338-52.e7.

112. Dwyer JM, Lepack $A E$, Duman RS. mTOR activation is required for the antidepressant effects of $\mathrm{mGluR}(2) /(3)$ blockade. Int J Neuropsychopharmacol. 2012;15:429-34.

113. Palucha-Poniewiera A, Podkowa K, Rafalo-Ulinska A. The group II mGlu receptor antagonist LY341495 induces a rapid antidepressant-like effect and enhances the effect of ketamine in the chronic unpredictable mild stress model of depression in C57BL/6J mice. Prog Neuropsychopharmacol Biol Psychiatry. 2021;109:110239.

114. Chaki S. The potential of group II metabotropic glutamate receptor antagonists as a novel antidepressant. Nihon Shinkei Seishin Yakurigaku Zasshi. 2012;32:219-26.

115. Chaki S. mGlu2/3 receptor antagonists as novel antidepressants. Trends Pharmacol Sci. 2017;38:569-80.

116. Huang $L, X i Y$, Peng $Y$, Yang $Y$, Huang $X, F u ~ Y$, et al. A visual circuit related to habenula underlies the antidepressive effects of light therapy. Neuron. 2019;102:128-42.e8.

117. Kaiser C, Kaufmann C, Leutritz T, Arnold YL, Speck O, Ullsperger M. The human habenula is responsive to changes in luminance and circadian rhythm. Neuroimage. 2019;189:581-8.

118. Klein ME, Chandra J, Sheriff S, Malinow R. Opioid system is necessary but not sufficient for antidepressive actions of ketamine in rodents. Proc Natl Acad Sci USA. 2020;117:2656-62.

119. Yang Y, Cui Y, Sang K, Dong Y, Ni Z, Ma S, et al. Ketamine blocks bursting in the lateral habenula to rapidly relieve depression. Nature. 2018;554:317-22.

120. Liu H, Rastogi A, Narain $P, X u$ Q, Sabanovic M, Alhammadi AD, et al. Blunted diurnal firing in lateral habenula projections to dorsal raphe nucleus and delayed photoentrainment in stress-susceptible mice. PLOS Biol. 2021;19: e3000709.

121. Thomas GM, Huganir RL. MAPK cascade signalling and synaptic plasticity. Nat Rev Neurosci. 2004;5:173-83.

122. Eckel-Mahan KL, Phan T, Han S, Wang H, Chan GC, Scheiner ZS, et al. Circadian oscillation of hippocampal MAPK activity and CAMP: implications for memory persistence. Nat Neurosci. 2008;11:1074-82. 
123. Reus GZ, Vieira FG, Abelaira HM, Michels M, Tomaz DB, dos Santos MA, et al. MAPK signaling correlates with the antidepressant effects of ketamine. J Psychiatr Res. 2014;55:15-21.

124. Barthas F, Humo M, Gilsbach R, Waltisperger E, Karatas M, Leman S, et al. Cingulate overexpression of mitogen-activated protein kinase phosphatase- 1 as a key factor for depression. Biol Psychiatry. 2017;82:370-9.

125. Kondoh K, Nishida E. Regulation of MAP kinases by MAP kinase phosphatases. Biochim Biophys Acta. 2007;1773:1227-37.

126. Jeanneteau F, Deinhardt K, Miyoshi G, Bennett AM, Chao MV. The MAP kinase phosphatase MKP-1 regulates BDNF-induced axon branching. Nat Neurosci. 2010;13:1373-9.

127. Duric V, Banasr M, Licznerski P, Schmidt HD, Stockmeier CA, Simen AA, et al. A negative regulator of MAP kinase causes depressive behavior. Nat Med. 2010;16:1328-32.

128. Humo M, Ayazgök B, Becker LJ, Waltisperger E, Rantamäki T, Yalcin I. Ketamine induces rapid and sustained antidepressant-like effects in chronic pain induced depression: Role of MAPK signaling pathway. Prog Neuro-Psychopharmacol Biol Psychiatry. 2020;100:109898.

129. Doi M, Cho S, Yujnovsky I, Hirayama J, Cermakian N, Cato AC, et al. Lightinducible and clock-controlled expression of MAP kinase phosphatase 1 in mouse central pacemaker neurons. J Biol Rhythms. 2007;22:127-39.

130. Mongrain V, La Spada F, Curie T, Franken P. Sleep loss reduces the DNA-binding of BMAL1, CLOCK, and NPAS2 to specific clock genes in the mouse cerebral cortex. PLoS ONE. 2011;6:e26622.

131. Sahar S, Zocchi L, Kinoshita C, Borrelli E, Sassone-Corsi P. Regulation of BMAL1 protein stability and circadian function by GSK3 $\beta$-mediated phosphorylation. PloS ONE. 2010;5:e8561.

132. Besing RC, Rogers CO, Paul JR, Hablitz LM, Johnson RL, McMahon LL, et al. GSK3 activity regulates rhythms in hippocampal clock gene expression and synaptic plasticity. Hippocampus. 2017;27:890-8.

133. Besing RC, Paul JR, Hablitz LM, Rogers CO, Johnson RL, Young ME, et al. Circadian rhythmicity of active GSK3 isoforms modulates molecular clock gene rhythms in the suprachiasmatic nucleus. J Biol Rhythms. 2015;30:155-60.

134. Beurel E, Song L, Jope RS. Inhibition of glycogen synthase kinase-3 is necessary for the rapid antidepressant effect of ketamine in mice. Mol Psychiatry. 2011;16:1068-70.

135. Costemale-Lacoste J-F, Colle R, Martin S, Asmar KE, Loeb E, Feve B, et al. Glycogen synthase kinase- $3 \beta$ genetic polymorphisms and insomnia in depressed patients: a prospective study. J Affect Disord. 2018;240:230-6.

136. Deyama S, Duman RS. Neurotrophic mechanisms underlying the rapid and sustained antidepressant actions of ketamine. Pharmacol Biochem Behav. 2020;188:172837.

137. Malberg JE, Hen R, Madsen TM. Adult neurogenesis and antidepressant treatment: the surprise finding by ron duman and the field 20 years later. Biol Psychiatry. 2021;90:96-101.

138. Ma Z, Zang T, Birnbaum SG, Wang Z, Johnson JE, Zhang C-L, et al. TrkB dependent adult hippocampal progenitor differentiation mediates sustained ketamine antidepressant response. Nat Commun. 2017;8:1668.

139. Hill AS, Sahay A, Hen R. Increasing adult hippocampal neurogenesis is sufficient to reduce anxiety and depression-like behaviors. Neuropsychopharmacology. 2015;40:2368-78.

140. Planchez B, Surget A, Belzung C. Adult hippocampal neurogenesis and antidepressants effects. Curr Opin Pharmacol. 2020;50:88-95.

141. Soumier A, Carter RM, Schoenfeld TJ, Cameron HA. New hippocampal neurons mature rapidly in response to ketamine but are not required for its acute antidepressant effects on neophagia in rats. eNeuro. 2016:3:1-13.

142. Kwon SJ, Park J, Park SY, Song KS, Jung ST, Jung SB, et al. Low-intensity treadmill exercise and/or bright light promote neurogenesis in adult rat brain. Neural Regen Res. 2013;8:922.

143. Li Y, Li G, Li J, Cai X, Sun Y, Zhang B, et al. Depression-like behavior is associated with lower Per2 mRNA expression in the lateral habenula of rats. Genes Brain Behav. 2021;20:e12702.

144. Gage FH. Adult neurogenesis in mammals. Science. 2019;364:827-8.

145. Pilz G-A, Bottes S, Betizeau M, Jörg DJ, Carta S, Simons BD, et al. Live imaging of neurogenesis in the adult mouse hippocampus. Science. 2018;359:658-62.

146. Kim JY, Liu CY, Zhang F, Duan X, Wen Z, Song J, et al. Interplay between DISC1 and $G A B A$ signaling regulates neurogenesis in mice and risk for schizophrenia. Cell. 2012;148:1051-64.

147. Sahay A, Hen R. Adult hippocampal neurogenesis in depression. Nat Neurosci. 2007;10:1110.

148. Koo JW, Russo SJ, Ferguson D, Nestler EJ, Duman RS. Nuclear factor-KB is a critical mediator of stress-impaired neurogenesis and depressive behavior. Proc Natl Acad Sci. 2010;107:2669-74.
149. Anacker C, Zunszain PA, Cattaneo A, Carvalho LA, Garabedian MJ, Thuret S, et al. Antidepressants increase human hippocampal neurogenesis by activating the glucocorticoid receptor. Mol Psychiatry. 2011;16:738-50.

150. Aguilar-Arnal L, Sassone-Corsi P. Stem cells: the clock within. Nature. 2011;480:185-7.

151. Bouchard-Cannon $P$, Mendoza-Viveros L, Yuen A, Kærn M, Cheng, H-Ying M. The circadian molecular clock regulates adult hippocampal neurogenesis by controlling the timing of cell-cycle entry and exit. Cell Rep. 2013;5:961-73.

152. Mogi A, Yomoda R, Kimura S, Tsushima C, Takouda J, Sawauchi M, et al. Entrainment of the circadian clock in neural stem cells by epidermal growth factor is closely associated with ERK1/2-mediated induction of multiple clockrelated genes. Neuroscience. 2018;379:45-66.

153. Benitah SA, Welz P-S. Circadian regulation of adult stem cell homeostasis and aging. Cell Stem Cell. 2020;26:817-31.

154. Akers KG, Chérasse $Y$, Fujita $Y$, Srinivasan $S$, Sakurai $T$, Sakaguchi M. Concise review: regulatory influence of sleep and epigenetics on adult hippocampal neurogenesis and cognitive and emotional function. Stem Cells. 2018;36: 969-76.

155. Ables JL, Breunig JJ, Eisch AJ, Rakic P. Not(ch) just development: notch signalling in the adult brain. Nat Rev Neurosci. 2011;12:269-83.

156. Karpowicz $P$, Zhang $Y$, Hogenesch JB, Emery P, Perrimon N. The circadian clock gates the intestinal stem cell regenerative state. Cell Rep. 2013;3:996-1004.

157. Janich P, Pascual G, Merlos-Suárez A, Batlle E, Ripperger J, Albrecht U, et al. The circadian molecular clock creates epidermal stem cell heterogeneity. Nature. 2011;480:209-14.

158. Ivanov D. Notch signaling-induced oscillatory gene expression may drive neurogenesis in the developing retina. Front Mol Neurosci. 2019;12:1-20.

159. Zhang R, Boareto $M$, Engler A, Louvi A, Giachino C, lber D, et al. Id4 downstream of Notch2 maintains neural stem cell quiescence in the adult hippocampus. Cell Rep. 2019;28:1485-98.e6.

160. Dong C, Rovnaghi CR, Anand K. Ketamine alters the neurogenesis of rat cortical neural stem progenitor cells. Crit Care Med. 2012;40:2407.

161. Nilsson EK, Bostrom AE, Mwinyi J, Schioth HB. Epigenomics of total acute sleep deprivation in relation to genome-wide DNA methylation profiles and RNA expression. OMICS. 2016;20:334-42.

162. Clarke M, Razmjou S, Prowse N, Dwyer Z, Litteljohn D, Pentz R, et al. Ketamine modulates hippocampal neurogenesis and pro-inflammatory cytokines but not stressor induced neurochemical changes. Neuropharmacology. 2017;112:210-20.

163. Yamada J, Jinno S. Potential link between antidepressant-like effects of ketamine and promotion of adult neurogenesis in the ventral hippocampus of mice. Neuropharmacology. 2019;158:107710.

164. Junek A, Rusak B, Semba K. Short-term sleep deprivation may alter the dynamics of hippocampal cell proliferation in adult rats. Neuroscience. 2010;170:1140-52.

165. Zucconi GG, Cipriani S, Balgkouranidou I, Scattoni R. 'One night'sleep deprivation stimulates hippocampal neurogenesis. Brain Res Bull. 2006;69:375-81.

166. Migita H, Kominami K, Higashida M, Maruyama R, Tuchida N, McDonald F, et al. Activation of adenosine $\mathrm{A} 1$ receptor-induced neural stem cell proliferation via MEK/ERK and Akt signaling pathways. J Neurosci Res. 2008;86:2820-8.

167. Wang Y, Xie L, Gao C, Zhai L, Zhang N, Guo L. Astrocytes activation contributes to the antidepressant-like effect of ketamine but not scopolamine. Pharmacol Biochem Behav. 2018;170:1-8.

168. Ardalan M, Rafati $A H$, Nyengaard JR, Wegener G. Rapid antidepressant effect of ketamine correlates with astroglial plasticity in the hippocampus. Br J Pharmacol. 2017;174:483-92.

169. Liu W-X, Wang J, Xie Z-M, Xu N, Zhang G-F, Jia M, et al. Regulation of glutamate transporter 1 via BDNF-TrkB signaling plays a role in the anti-apoptotic and antidepressant effects of ketamine in chronic unpredictable stress model of depression. Psychopharmacology. 2016;233:405-15.

170. Haim LB, Rowitch DH. Functional diversity of astrocytes in neural circuit regulation. Nat Rev Neurosci. 2016;18:31.

171. Stenovec M. Ketamine alters functional plasticity of astroglia: an implication for antidepressant effect. Life. 2021;11:573-89.

172. Kim J-W, Herz J, Kavalali ET, Monteggia LM. A key requirement for synaptic Reelin signaling in ketamine-mediated behavioral and synaptic action. Proc Natl Acad Sci. 2021:118:e2103079118.

173. Martins HC, Schratt G. MicroRNA-dependent control of neuroplasticity in affective disorders. Transl Psychiatry. 2021;11:263.

174. Huang C, Wang Y, Wu Z, Xu J, Zhou L, Wang D, et al. miR-98-5p plays a critical role in depression and antidepressant effect of ketamine. Transl Psychiatry. 2021;11:454.

175. Park SW, Lee JG, Seo MK, Cho HY, Lee CH, Lee JH, et al. Effects of moodstabilizing drugs on dendritic outgrowth and synaptic protein levels in primary hippocampal neurons. Bipolar Disord. 2015;17:278-90. 
176. Micheli L, Ceccarelli M, D'Andrea G, Tirone F. Depression and adult neurogenesis: positive effects of the antidepressant fluoxetine and of physical exercise. Brain Res Bull. 2018;143:181-93.

177. Griggs CA, Malm SW, Jaime-Frias R, Smith CL. Valproic acid disrupts the oscillatory expression of core circadian rhythm transcription factors. Toxicol Appl Pharmacol. 2018;339:110-20.

178. Kornhuber J, Gulbins E. New Molecular targets for antidepressant drugs. Pharmaceuticals. 2021;14:894-908.

179. Widman AJ, McMahon LL. Effects of ketamine and other rapidly acting antidepressants on hippocampal excitatory and inhibitory transmission. Adv Pharmacol. 2020;89:3-41.

180. Detanico BC, Piato AL, Freitas JJ, Lhullier FL, Hidalgo MP, Caumo W, et al. Antidepressant-like effects of melatonin in the mouse chronic mild stress model. Eur J Pharmacol. 2009;607:121-5.

181. Tonon AC, Pilz LK, Markus RP, Hidalgo MP, Elisabetsky E. Melatonin and depression: a translational perspective from animal models to clinical studies. Front Psychiatry. 2021;12:638981.

182. Colombo C, Benedetti F, Barbini B, Campori E, Smeraldi E. Rate of switch from depression into mania after therapeutic sleep deprivation in bipolar depression. Psychiatry Res. 1999;86:267-70.

183. Sit D, Wisner KL, Hanusa BH, Stull S, Terman M. Light therapy for bipolar disorder: a case series in women. Bipolar Disord. 2007;9:918-27.

184. Henriksen TEG, Gronli J, Assmus J, Fasmer OB, Schoeyen H, Leskauskaite I, et al. Blue-blocking glasses as additive treatment for mania: Effects on actigraphyderived sleep parameters. J Sleep Res. 2020;29:e12984.

185. Hashimoto S, Kohsaka M, Nakamura K, Honma H, Honma S, Honma K. Midday exposure to bright light changes the circadian organization of plasma melatonin rhythm in humans. Neurosci Lett. 1997;221:89-92.

186. Sit D, Haigh S. Use of "lights" for bipolar depression. Curr Psychiatry Rep. 2019;21:45.

187. Gold AK, Kinrys G. Treating circadian rhythm disruption in bipolar disorder. Curr Psychiatry Rep. 2019;21:14

188. Henriksen TE, Skrede S, Fasmer OB, Schoeyen H, Leskauskaite I, BjorkeBertheussen J, et al. Blue-blocking glasses as additive treatment for mania: a randomized placebo-controlled trial. Bipolar Disord. 2016;18:221-32.

189. Duncan WC Jr., Slonena EE, Hejazi NS, Brutsche N, Park LT, Henter ID, et al. Are 24-h motor activity patterns associated with continued rapid response to ketamine? Neuropsychiatr Dis Treat. 2018;14:2739-48.

190. Zhuo C, Tian H, Li G, Chen M, Jiang D, Lin X, et al. Effects of ketamine on circadian rhythm and synaptic homeostasis in patients with treatment-resistant depression: a protocol for mechanistic studies of its rapid and sustained antidepressant actions in humans. Brain Behav. 2019;9:e01423-33.

191. Cho CH, Lee T, Kim MG, In HP, Kim L, Lee HJ. Mood prediction of patients with mood disorders by machine learning using passive digital phenotypes based on the circadian rhythm: prospective observational cohort study. J Med Internet Res. 2019;21:e11029.

192. Schneider J, Bakstein E, Kolenic M, Vostatek P, Correll CU, Novak D, et al. Motor activity patterns can distinguish between interepisode bipolar disorder patients and healthy controls. CNS Spectr. 2020:1-11.

193. Zhang Y, Folarin AA, Sun S, Cummins N, Ranjan Y, Rashid Z, et al. Predicting depressive symptom severity through individuals' nearby bluetooth device count data collected by mobile phones: preliminary longitudinal study. JMIR Mhealth Uhealth. 2021;9:e29840.

194. Ferguson A, Lyall LM, Ward J, Strawbridge RJ, Cullen B, Graham N, et al. Genome-wide association study of circadian rhythmicity in 71,500 UK biobank participants and polygenic association with mood instability. EBioMedicine. 2018;35:279-87.

195. Melhuish Beaupre LM, Goncalves VF, Zai CC, Tiwari AK, Harripaul RS, Herbert D, et al. Genome-wide association study of sleep disturbances in depressive disorders. Mol Neuropsychiatry. 2020;5:34-43.

196. McCarthy MJ. Missing a beat: assessment of circadian rhythm abnormalities in bipolar disorder in the genomic era. Psychiatr Genet. 2019;29:29-36.

197. Levey DF, Polimanti R, Cheng Z, Zhou H, Nunez YZ, Jain S, et al. Genetic associations with suicide attempt severity and genetic overlap with major depression. Transl Psychiatry. 2019;9:22.

198. Soria V, Martinez-Amoros E, Escaramis G, Valero J, Perez-Egea R, Garcia C, et al Differential association of circadian genes with mood disorders: CRY1 and NPAS2 are associated with unipolar major depression and CLOCK and VIP with bipolar disorder. Neuropsychopharmacology. 2010;35:1279-89.

199. Hua P, Liu W, Chen D, Zhao Y, Chen L, Zhang N, et al. Cry1 and Tef gene polymorphisms are associated with major depressive disorder in the Chinese population. J Affect Disord. 2014;157:100-3.

200. Zhang $R$, Lahens NF, Ballance HI, Hughes ME, Hogenesch JB. A circadian gene expression atlas in mammals: implications for biology and medicine. Proc Natl Acad Sci USA. 2014;111:16219-24.
201. Noya SB, Colameo D, Brüning F, Spinnler A, Mircsof D, Opitz L, et al. The forebrain synaptic transcriptome is organized by clocks but its proteome is driven by sleep. Science. 2019;366:eaav2642.

202. Bruning F, Noya SB, Bange T, Koutsouli S, Rudolph JD, Tyagarajan SK, et al Sleep-wake cycles drive daily dynamics of synaptic phosphorylation. Science. 2019;366:eaav3617.

203. Mure LS, Le HD, Benegiamo G, Chang MW, Rios L, Jillani N, et al. Diurnal transcriptome atlas of a primate across major neural and peripheral tissues. Science. 2018;359:eaao0318.

204. Na YJ, Sung JH, Lee SC, Lee YJ, Choi YJ, Park WY, et al. Comprehensive analysis of microRNA-mRNA co-expression in circadian rhythm. Exp Mol Med. 2009;41:638-47.

205. Koike N, Yoo S-H, Huang H-C, Kumar V, Lee C, Kim T-K, et al. Transcriptional architecture and chromatin landscape of the core circadian clock in mammals. Science. 2012;338:349-54.

206. Cox KH, Takahashi JS. Circadian clock genes and the transcriptional architecture of the clock mechanism. J Mol Endocrinol. 2019;63:R93-102.

207. Karczewski KJ, Snyder MP. Integrative omics for health and disease. Nat Rev Genet. 2018;19:299-310.

208. Pizarro A, Hayer K, Lahens NF, Hogenesch JB. CircaDB: a database of mammalian circadian gene expression profiles. Nucleic Acids Res. 2013;41:D1009-13.

209. Li X, Shi L, Zhang K, Wei W, Liu Q, Mao F, et al. CirGRDB: a database for the genome-wide deciphering circadian genes and regulators. Nucleic acids Res. 2018;46:D64-70.

210. Patel VR, Eckel-Mahan K, Sassone-Corsi P, Baldi P. CircadiOmics: integrating circadian genomics, transcriptomics, proteomics and metabolomics. Nat Methods. 2012;9:772-3.

211. Mauvoisin D, Gachon F. Proteomics in circadian biology. J Mol Biol. 2020;432:3565-77.

212. Carpenter JS, Crouse JJ, Scott EM, Naismith SL, Wilson C, Scott J, et al. Circadian depression: a mood disorder phenotype. Neurosci Biobehav Rev. 2021;126:79-101.

213. Logan RW, Xue X, Ketchesin KD, Hoffman G, Roussos P, Tseng G, et al. Sex differences in molecular rhythms in the human cortex. Biol Psychiatry. 2021. In Press.

214. Athreya AP, Neavin D, Carrillo-Roa T, Skime M, Biernacka J, Frye MA, et al. Pharmacogenomics-driven prediction of antidepressant treatment outcomes: a machine-learning approach with multi-trial replication. Clin Pharmacol Ther. 2019;106:855-65.

215. Centers for Disease Control and Prevention 1999-2017 Suicide Injury Deaths and Rates per 100,000. (https://www.cdc.gov/nchs/fastats/suicide.htm). Accesed 20 Oct 2021.

216. American Foundation for Suicide Prevention (AFSP). Suicide facts and figures: United States 2020-2021. (https://afsp.org/suicide-statistics/). Acessed 20 Oct 2021.

217. Ehlers CL, Frank E, Kupfer DJ. Social Zeitgebers and biological rhythms: a unified approach to understanding the etiology of depression. Arch Gen Psychiatry. 1988:45:948-52.

218. Krishnan V, Nestler EJ. The molecular neurobiology of depression. Nature. 2008;455:894-902

219. Duncan WC, Slonena E, Hejazi NS, Brutsche N, Yu KC, Park L, et al. Motor-activity markers of circadian timekeeping are related to ketamine's rapid antidepressant properties. Biol Psychiatry. 2017;82:361-9.

220. Verwey M, Dhir S, Amir S. Circadian influences on dopamine circuits of the brain: regulation of striatal rhythms of clock gene expression and implications for psychopathology and disease. F1000Res. 2016;5:F1000 Faculty Rev-2062.

221. Barca Mayo O, Berdondini L, De Pietri Tonelli D. Astrocytes and circadian rhythms: an emerging astrocyte-neuron synergy in the timekeeping system. In: Di Benedetto B, editor. Astrocytes: methods and protocols. New York, NY: Springer New York; 2019. p. 131-54.

222. Beaulieu J-M, Zhang X, Rodriguiz RM, Sotnikova TD, Cools MJ, Wetsel WC, et al. Role of GSK3 $\beta$ in behavioral abnormalities induced by serotonin deficiency. Proc Natl Acad Sci. 2008;105:1333-8.

223. Yin L, Wang J, Klein PS, Lazar MA. Nuclear receptor Rev-erba is a critical lithiumsensitive component of the circadian clock. Science. 2006;311:1002-05.

224. Liu R-J, Fuchikami M, Dwyer JM, Lepack AE, Duman RS, Aghajanian GK. GSK-3 inhibition potentiates the synaptogenic and antidepressant-like effects of subthreshold doses of ketamine. Neuropsychopharmacology. 2013;38:2268-77.

225. Inoki K, Ouyang H, Zhu T, Lindvall C, Wang Y, Zhang X, et al. TSC2 integrates Wnt and energy signals via a coordinated phosphorylation by AMPK and GSK3 to regulate cell growth. Cell. 2006;126:955-68.

226. Beaulieu J-M, Tirotta E, Sotnikova TD, Masri B, Salahpour A, Gainetdinov RR, et al. Regulation of Akt signaling by D2 and D3 dopamine receptors in vivo. J Neurosci. 2007;27:881-5.

227. Wu R, Dang F, Li $P$, Wang $P, X u ~ Q$, Liu $Z$, et al. The circadian protein Period2 suppresses mTORC1 activity via recruiting Tsc1 to mTORC1 complex. Cell Metab. 2019;29:653-67.e6. 
228. Sato S, Bunney BG, Vawter MP, Bunney WE, Sassone-Corsi P. Homer1a undergoes bimodal transcriptional regulation by CREB and the circadian clock. Neuroscience. 2020;434:161-70.

\section{ACKNOWLEDGEMENTS}

As this review was about to be submitted, we were shocked and saddened to learn of the unexpected and sudden passing of PSC. It was an honor for us to have the opportunity to work on this review with PSC, who was an outstanding scientist in the field of circadian research and a great mentor.

\section{AUTHOR CONTRIBUTIONS}

$B B, W B, E B, P S C$ and ROS conceptualized and wrote the paper. SS and LMV contributed with critical suggestions. All authors edited the paper.

\section{FUNDING}

This work was supported by founds from the CONACYT grants FC 2016/2672 and FOSISS 272757 and the INMEGEN (09/2017/I). LMV, was supported by a fellowship from CONACYT (740445, 27048), DGAPA-UNAM and a L'Oréal-UNESCO-Mexican Academy of Sciences (AMC) fellowship for Women in Science. SS was supported by a fellowship from the Della Martin Foundation and a grant from the Brain \& Behavior Research Foundation (NARSAD Young Investigator Grant, 28681).

\section{COMPETING INTERESTS}

The authors declare no competing interests.

\section{ADDITIONAL INFORMATION}

Correspondence and requests for materials should be addressed to Ricardo OrozcoSolis.

Reprints and permission information is available at http://www.nature.com/ reprints

Publisher's note Springer Nature remains neutral with regard to jurisdictional claims in published maps and institutional affiliations. 